\title{
LA POSIBLE AUTORÍA DEL MANUSCRITO ANÓNIMO PHRASES SELECTAS, ENTRE EL UNO Y EL MÚLTIPLE (MISIONES JESUÍTICAS DE GUARANÍES, SIGLO XVII)
}

\author{
The Possible Authorship of an Anonymous Manuscript between One and \\ Multiple (Jesuit Guarani Missions, 17th Century)
}

Fabián R. Vega*

https://orcid.org/0000-0003-4133-5053

\section{Resumen}

El presente artículo estudia la autoría del manuscrito Phrases Selectas, un diccionario castellano-guaraní elaborado en las misiones jesuíticas de guaraníes a fines del siglo XVII. Contrastamos la información que el propio manuscrito aporta sobre su contexto de enunciación y los datos sobre los misioneros del Paraguay presentes en los catálogos de la Compañía de Jesús. De este modo, reunimos los indicios que establece la probabilidad de que el "autor principal" del manuscrito sea el jesuita italiano José Coco. Asimismo, postulamos la necesidad de elaborar un marco interpretativo de autoría múltiple y compleja para este y otros manuscritos en guaraní del Paraguay jesuítico. A partir de estos dos postulados, sugerimos que la producción textual jesuítico-guaraní fue llevada adelante por una constelación más amplia de lenguaraces de lo que tradicionalmente se ha creído y no únicamente por figuras individuales de genio.

$$
<\text { Misiones Jesuíticas }><\text { Lengua Guaraní }><\text { Manuscritos }><\text { Autoría }>
$$

\begin{abstract}
This article inquires into the authorship of the manuscript Phrases Selectas, a Spanish-Guarani dictionary composed in the Jesuit-Guarani missions at the end of the 17th century. We compare the information provided by the manuscript about its context of enunciation with the data related to the missionaries of the Paraguay included in the catalogues of the Society of Jesus. In this manner, we gather the evidence that suggests that the "main author" of the manuscript is the Italian Jesuit José Coco. Moreover, we highlight the need to build an interpretative framework of multiple and complex authorship for this and other manuscripts in Guarani language from the Jesuit Paraguay. Based on these two assertions, we propose that the Jesuit-Guarani textual production was composed by a broader group of linguistic specialists than previously believed and not just by learned individuals.
\end{abstract}

$$
<\text { Jesuit Missions }><\text { Guarani Language }><\text { Manuscripts }><\text { Authorship }>
$$

Recibido: 21/08/2018//Aceptado: 07/10/2018

\footnotetext{
* Instituto de Altos Estudios Sociales (IDAES), Universidad Nacional de San Martín (UNSAM). Becario Doctoral del Consejo Nacional de Investigaciones Científicas y Técnicas (CONICET), Argentina, vegafabianr@gmail.com
} 
Vega. La posible autoría del manuscrito anónimo Phrases Selectas, entre el uno y el múltiple (Misiones Jesuíticas de...

\section{Presentación}

En el presente artículo analizamos la autoría del manuscrito Phrases Selectas, un diccionario guaraní-castellano elaborado en el contexto de las misiones jesuíticas de guaraníes a finales del siglo XVII. Como tal, este manuscrito es una manifestación particular de una cultura textual misional más amplia, que contó como uno de sus componentes relevantes la relativamente vasta producción textual en lengua guaraní, elaborada tanto por los jesuitas como por los indígenas. Los tipos de textos producidos en lengua guaraní son variados; entre los de mayor extensión existen relatos históricos, libros botánicos y medicinales y producciones catequísticas, espirituales y teológicas de diverso tipo. La producción específicamente lingüística es una de las fracciones más conocidas de esta cultura textual misional. En efecto, en las misiones jesuíticas de guaraníes se escribieron gramáticas y diccionarios guaraní-castellano o castellanoguaraní. Estos textos, que circularon como manuscritos y también impresos, tienen una importancia fundamental porque aportan pistas tanto sobre el proceso de interacción entre misioneros e indígenas como acerca de la invención de esquemas y conceptos por parte de los jesuitas para su propia práctica misional. En este último sentido, el corpus lingüístico permite revelar algunas claves acerca de la política específicamente lingüística de los jesuitas, acerca de quiénes la llevaron adelante y sobre qué tan extendida estuvo la experticia lingüística entre los misioneros.

El objetivo de este artículo es explorar un aspecto puntual de esta cultura textual: la posible atribución autoral del manuscrito Phrases Selectas. Se pretende identificar con precisión al jesuita que actuó como el organizador principal del material lingüístico del documento a través de los datos que aportan al respecto los paratextos del libro. En este sentido, juzgamos que la información allí presente - comparada con la incluida en los catálogos de personal de la Compañía de Jesús - es suficiente para postular que este jesuita fue el poco conocido misionero José Coco (1643-1717), también llamado José Tolo o Tolu. Asimismo, se aclara que este jesuita no es desde luego el único que contribuyó a producir el manuscrito, puesto que en el mismo documento existen indicios del rol de los informantes lingüísticos y de los copistas indígenas, además de la relevancia del texto de base (reescrito y actualizado) de Antonio Ruiz de Montoya. En conjunto, pretendemos que la exploración puntual presentada en este artículo pueda servir para completar el panorama relativo a la estructura de especialistas en la lengua guaraní existentes en las reducciones jesuíticas del Paraguay, un aspecto central en la historia cultural de este espacio en la medida en que los jesuitas consideraban que la maestría en la lengua era la condición de la convertibilidad religiosa.

En las grandes líneas de investigación de los estudios literarios y de la historia cultural se ha prestado una gran atención a la discusión sobre la autoría (Barthes, 1994; Chartier, 1994; Chartier, 1996 y Foucault, 2010). A pesar de la pertinencia de estos debates, los alcances limitados de este artículo nos impiden ingresar en la complejidad teórica de los mismos. Baste en este sentido destacar que en la modernidad temprana la noción de autoría era diferente de aquella que se desarrolló en los siglos XIX y XX, puesto que subjetividad y originalidad no eran nociones asignadas a la idea de autor en 
la cultura retórica de la época, mucho menos en el marco de textos cuya finalidad era la evangelización de poblaciones indígenas. En este sentido, es fundamental resaltar que no es adecuado valerse de una interpretación "en la clave romántica e iluminística que gobierna los cánones literarios contemporáneos” (Daher, 2011, p. 77) para interpretar el corpus lingüístico y catequístico en guaraní, puesto que ese tipo de lecturas terminan silenciando el objetivo salvífico de estos materiales - objetivo mucho más relevante que el reconocimiento de un anacrónico "genio" productor de los documentos-. Por otro lado, para algunos textos en guaraní producidos en las misiones se ha postulado la idea de una "traducción paradojal" que alude a la presencia constante de colaboradores indígenas cuyo estatuto autoral permanece a menudo invisibilizado (Brignon, 2018). La impresión, a partir del nombre estampado en la portada, es una de las herramientas centrales de (auto)atribución autoral de estos textos. En el caso del manuscrito Phrases Selectas, la portada que imita a una impresa tan solo otorga estatuto autoral a Antonio Ruiz de Montoya, a pesar de lo cual es evidente que por lo menos otro jesuita, de fines del siglo XVII, se encargó de reorganizar y actualizar el material lingüístico sobre la base de Ruiz de Montoya. Ahora bien, el objetivo de este trabajo no es tanto "descubrir" a un "autor" desconocido como comprender más en profundidad la circulación de conocimientos lingüísticos entre los jesuitas. En este sentido, la problemática de la atribución de Phrases Selectas sólo intenta contribuir a profundizar esa comprensión ${ }^{1}$.

\section{La lengua guaraní y la producción lingüística jesuítica en el siglo XVII}

La cultura textual desarrollada en el complejo misional jesuítico-guaraní está íntimamente relacionada con las tareas de evangelización llevadas adelante por los jesuitas. En este sentido, cabe suponer que para los misioneros no existía una distinción entre la elaboración de textos que hoy consideramos religiosos (por ejemplo, un sermón o un catecismo) y la redacción de libros que hoy juzgaríamos lingüísticos (como gramáticas y diccionarios). La finalidad a la que respondían ambas posibilidades textuales era la misma (Daher, 2011y Melià, 2003, pp. 157-206) en la medida en que existe una coextensividad entre conversión lingüística y religiosa. El aprendizaje lingüístico de los jesuitas y otros miembros de órdenes religiosas, a menudo retomado para el estudio de la concepción de los religiosos sobre la alteridad cultural, responde en primer lugar a las necesidades prácticas de la conversión.

La producción lingüístico-religiosa en el espacio jesuítico-guaraní forma parte de un fenómeno que tiene lugar a escala de toda la América ibérica: la "reducción" a gramática y puesta por escrito de las lenguas indígenas. Se trata de un proceso en el que ocupan un rol fundamental las lenguas generales coloniales (Castelnau L'Estoile, 2015 y Estenssoro, 2015). De acuerdo a Estenssoro e Itier, estas lenguas generales deben ser claramente distinguidas de las lenguas indígenas prehispánicas, puesto que las primeras fueron instrumentos para construir "una progresiva homogeneización

Sobre las implicaciones analíticas de este trabajo heurístico, y su complementación con estudios hermenéuticos, véase (Illari, 2006). 
Vega. La posible autoría del manuscrito anónimo Phrases Selectas, entre el uno y el múltiple (Misiones Jesuíticas de...

etnocultural $^{2 "}$ en el marco imperial establecido por los colonizadores (Estenssoro e Itier, 2015). A pesar de la idea tradicional de Antonio de Nebrija relativa a la lengua (castellana) como compañera del imperio, este proceso implicó la formulación de una triple jerarquía funcional de idiomas, que incluye ciertamente en primer lugar a las lenguas metropolitanas (español y portugués), en segundo lugar a las lenguas generales - que pueden articular un espacio amplio (como el quechua o el tupí) o un territorio más reducido (como el guaraní) - y en tercer lugar "cientos de lenguas de porte local a las que los gramáticos, lexicógrafos y predicadores europeas prestan una atención limitada" o nula ${ }^{3}$. Esta jerarquía lingüística resulta pues fundamental en el proceso de dominación imperial y colonial. El surgimiento y desarrollo de una cultura textual en un determinado idioma (en el caso aquí considerado, el guaraní) es uno de los factores, entre otros, que contribuye a establecer a este como lengua general colonial. No obstante, este desarrollo tiene también una dimensión exegética y teológica que no debe desconocerse, en el sentido de que la puesta en escrito de una lengua indígena era concebida como un proceso que la acercaba al idioma adánico original, posibilitando así la comunicación con Dios y la evangelización (Daher, 2011).

El tupí-guaraní era un idioma hablado en amplias regiones, desde la costa atlántica de Brasil hasta las estribaciones de los Andes en la actual Bolivia, especialmente como consecuencia de las migraciones de las poblaciones indígenas hacia ese territorio fronterizo. En el caso del "guaraní del sur" — como podría conocerse a la lengua de las zonas equivalentes a los actuales sudeste de Brasil, noreste de Argentina y Paraguay (en oposición al tupí de regiones ubicadas un poco más al norte) — el trabajo lingüístico se inició de la mano del franciscano Luis de Bolaños ${ }^{4}$, quien arribó a Asunción en 1575. Luis de Bolaños fue el primer europeo en llevar adelante la escritura sistemática de textos en guaraní. En este sentido, el franciscano redactó un catecismo breve y una doctrina (un catecismo más extenso) (Melià, 2003, pp. 17-42). Dos textos de Luis de Bolaños fueron impresos en la compilación Rituale, seu manuale peruanum (1607) publicada en Nápoles por Luis Jerónimo Oré.

Aunque este libro no fue registrado en los inventarios de las bibliotecas de las misiones de guaraníes y de los colegios jesuíticos del Paraguay (elaborados después de 1767$)^{5}$, los manuscritos de Bolaños circularon entre los primeros jesuitas que

2 En francés en el original: "une progressive homogénéisation ethnoculturelle" (traducción propia).

3 En francés en el original: "centaines de langues de portée locale auxquelles les grammairiens, lexicographes et prédicateurs européens prêtent une attention limitée" (traducción propia).

4 Luis de Bolaños nació en Andalucía (España) en 1539, se embarcó hacia América en 1572 y arribó a Asunción en 1575. Falleció en Buenos Aires en 1629 (Udaondo, 1945,162-164).

5 Estos inventarios se encuentran dispersos en el Archivo General de la Nación (Buenos Aires, Argentina) y en el Archivo Nacional de Chile (Santiago de Chile). Entre los primeros véase los siguientes legajos del Fondo de Temporalidades: IX-07-03-07 (Buenos Aires); IX-22-01-02, IX-22-01-03, IX-22-01-04, IX22-01-06 (Salta); IX-22-03-01 (Mendoza); IX-22-03-05, IX-22-03-06, IX-22-04-01 (Santa Fe); IX-2204-02 (Catamarca); IX-22-05-01, IX-22-05-03 (Santiago del Estero); IX-22-06-01 (Jujuy); IX-22-06-05, IX-22-06-07 (Corrientes); IX-22-07-02 (La Rioja); IX-22-07-03 (San Luis); IX-22-09-01 (Asunción); IX-22-09-03 (Montevideo); IX-22-06-03, IX-22-06-04, IX-22-09-04 (reducciones de guaraníes). Entre los legajos de Chile, correspondiente al fondo Jesuitas, véase los volúmenes: 140, 141, 142, 143 y 145 (los cinco sobre reducciones de guaraníes); 146 (Montevideo, La Rioja); 147 (Tucumán, La Rioja, 
evangelizaron en la región desde principios del siglo XVII. Francisco de San Martín 6 indicó en abril de 1610 que sus estudios de guaraní, así como las notas que efectuaba al margen de los textos, se basaban en manuscritos de Luis de Bolaños y en el libro sobre tupí de José de Anchieta (Arte de grammatica da lingoa mais usada na costa do Brasil, 1595) ${ }^{7}$. Además, los primeros misioneros elaboraban sus propios apuntes lingüísticos. Así, por ejemplo, en la carta anua de 1609-1614 el jesuita Diego de Torres ${ }^{8}$ alude a "papelillos de la lengua que había escrito" (Leonhardt, 1927, p. 177) y que no pudo conservar. Además, ya desde las primeras décadas del siglo XVII algunos jesuitas llevaron adelante un trabajo más serio acerca del idioma. Entre estos, cabe destacar a Marciel de Lorenzana ${ }^{9}$, Alonso de Barzana ${ }^{10}$, Diego González Holguín ${ }^{11}$ y Roque González de Santa Cruz ${ }^{12}$. Todos estos jesuitas escribieron distintos apuntes gramaticales que no se han conservado (Melià, 1992, pp. 83-89). Por su parte, Alonso d'Aragona 13 escribió una "Breve introducción para aprender la lengua guaraní", que consiste en un esquema gramatical de la lengua y que fue dado a conocer hace algunas décadas por Bartomeu Melià (1979).

La producción de Antonio Ruiz de Montoya $^{14}$ es la coronación de todo este trabajo lingüístico. Ruiz de Montoya es el primer gran cronista y propagandista de las misiones de guaraníes - a través de la obra Conquista espiritual - y es también el autor de los primeros textos extensos en o sobre guaraní que alcanzaron la imprenta. En efecto, Ruiz de Montoya redactó un Tesoro de la lengua guaraní (1639), un Arte, y bocabulario de la lengua guaraní (1640) y un Catecismo de la lengua guaraní (1640),

Asunción); 148 (San Luis, Mendoza); 149 (Salta); 150 (Chaco y también reducciones de guaraníes); 151 (Santiago del Estero); y 152 (Santiago del Estero, Salta, Jujuy). Los catálogos e inventarios de las bibliotecas de Asunción y Córdoba se encuentran editados (Fraschini, 2005a; Fraschini, 2005b; Gorzalczany y Olmos Gaona, 2006; Lovay, 2017). También existe una edición de los inventarios de las reducciones de guaraníes que no es completa (Brabo, 1872).

6 Francisco de San Martín nació en Novés (Toledo, España) en 1581, arribó a Buenos Aires en 1608 y en 1616 abandonó la Compañía de Jesús. No se conoce su fecha de muerte (Storni, 1980, 261).

7 Roma. Archivum Romanum Societatis Iesu (ARSI), Paraq. 11. "Copia de una carta del Pe. Fran ${ }^{\text {co }}$ de S. Martin dela mision del Parana", ff. 69 r-v.

8 Diego de Torres nació en Villalpando (Zamora, España) en 1551, viajó junto a otros jesuitas a Perú, en donde emitió su cuarto voto como miembro de la Compañía en 1588, y fue el fundador y primer provincial de la provincia jesuítica del Paraguay en 1607. Falleció en Sucre en 1638 (Storni, 1980, 286).

9 Marciel de Lorenzana nació en León (España) en 1565, arribó al Paraguay en 1593 y falleció en Asunción en 1632 (Storni, 1980, 194).

${ }^{10}$ Alonso de Barzana nació en España en 1530, viajó junto a otros jesuitas a Perú y emitió su cuarto voto en este territorio en 1576. A fines del siglo XVI misionó en territorio actualmente argentino. Falleció en Cuzco en 1597 (Storni, 1980, 32-33).

${ }^{11}$ Diego González Holguín nació en Cáceres (España) en 1553, arribó al Paraguay en 1608 y falleció en Mendoza en 1617 (Storni, 1980, 122).

${ }^{12}$ Roque González de Santa Cruz nació en Asunción en 1576 y falleció en el territorio actual de Rio Grande do Sul (Brasil) en 1628 (Storni, 1980,126).

${ }^{13}$ Alonso d' Aragona nació en Nápoles (Italia) en 1585, arribó a Buenos Aires en 1617 y falleció en Asunción en 1628 (Storni, 1980,76).

${ }^{14}$ Antonio Ruiz de Montoya nació en Lima en 1585 y falleció en la misma ciudad en 1652. Fue superior de las misiones de guaraníes entre 1636 y 1637 (Storni, 1980, p. 253) y procurador del Paraguay en España entre 1638 y 1643. 
Vega. La posible autoría del manuscrito anónimo Phrases Selectas, entre el uno y el múltiple (Misiones Jesuíticas de...

todos los cuales fueron impresos en Madrid durante el período en que se desempeñó como procurador (1638-1643). Este misionero llevó adelante la verdadera "reducción" lingüística del idioma: no sólo elaboró una gramática del mismo, sino que también redactó los diccionarios castellano-guaraní y guaraní-castellano. Asimismo, escribió un catecismo, aunque como lo indicamos ya existía una versión anterior de Bolaños. La política lingüística jesuítica generó un airado debate en el Paraguay y el Río de la Plata a mediados del siglo XVII, puesto que el obispo de Asunción, el franciscano Bernardino de Cárdenas ${ }^{15}$, cuestionó el uso de determinadas palabras de la lengua guaraní para transmitir el mensaje cristiano, por ejemplo, la expresión Tupã para referirse a Dios. Aunque el resultado político de esta polémica fue favorable a los jesuitas, es en este contexto que Ruiz de Montoya redactó su último texto conocido, una Apología en defensa del catecismo en guaraní, considerada por Melià como "uno de los grandes textos lingüísticos del siglo XVII” (sobre la especificidad lingüística del debate, véase Melià, 2003, pp. 209-260 y Wilde, 2016, pp. 34-39) ${ }^{16}$.

La importancia de la figura de Ruiz de Montoya es imposible de negar. Él era considerado el "autor" por excelencia de la producción lingüística sobre el guaraní. Su nombre figura en la portada de muchos de los libros - impresos y manuscritosestrictamente lingüísticos que produjeron los jesuitas desde mediados del siglo XVII hasta la expulsión, puesto que en el marco de la cultura retórica y teológica de la época todos estos textos eran considerados compendios, extractos o reescrituras de la obra base de Ruiz de Montoya. Así, en las reducciones de guaraníes se imprimieron, en la década de 1720, dos textos lingüísticos: el Vocabulario de la lengua guaraní de 1722 y el Arte de la lengua guaraní de 1724. La portada del primero indica que fue "compuesto por el Padre Antonio Ruiz" y "revisto y aumentado por otro religioso" jesuita. La portada del segundo atribuye el libro también a Ruiz de Montoya, aunque con "escolios, anotaciones y apéndices" de Pablo Restivo, "sacados de los papeles del P. Simón Bandini y de otros" ${ }^{\prime 1}$. Sabemos que Restivo tuvo un rol de organizador (revisor y anotador, según las portadas) de estos libros, pero en los dos casos su nombre aparece opacado en la portada por el de Ruiz de Montoya. Por lo demás, de acuerdo a los inventarios que se elaboraron en 1768 y después, existían en el conjunto de la provincia jesuítica del Paraguay unos 90 manuscritos ${ }^{18}$. De estos, al menos 14 correspondían a temas lingüísticos; carecemos de

${ }^{15}$ Bernardino de Cárdenas nació en Chuquiagu (La Paz, Bolivia) en 1579. Fue presentado para ocupar el obispado del Paraguay en 1638 y se consagró en 1641. Fue elegido gobernador de Asunción en 1649. Falleció en La Paz en 1670 (Udaondo, 1945, pp. 215-216).

${ }^{16}$ Desde luego, la cuestión lingüística no fue el único problema. Para una interpretación más general, que enfatiza la alianza de los criollos asuncenos con el obispo de Cárdenas en el marco de un conflicto de larga data por la distribución de los recursos locales con la Compañía de Jesús, véase la obra de Mercedes Avellaneda (Avellaneda, 2014, pp. 63-127).

${ }^{17}$ Esto da cuenta de que tal vez el jesuita veneciano Simón Bandini —o Vandini según la grafía utilizada por Storni (Storni, 1980, p. 296)- (1607-1679) también haya escrito textos lingüísticos. En principio, sólo se conoce de su parte la redacción de una serie de doctrinas, incluidas en el volumen manuscrito Catecismos varios.

${ }^{18}$ Además, hemos contabilizado 188 libros en o sobre guaraní de los que carecemos de información sobre si se trataba de impresos o manuscritos. Es altamente probable que por lo menos una parte de este grupo fuese manuscrito. De estos 188 libros, al menos 49 eran sobre contenido lingüístico. 
información sobre el contenido de otros 55 de estos manuscritos, pero resulta probable que al menos algunos de estos fuesen también diccionarios y gramáticas. Tal vez varios correspondan a las primeras décadas del siglo XVII, pero hoy en día conocemos muchos manuscritos posteriores, además de Phrases Selectas: un Arte de la lengua guaraní de 1696 firmado por "Blas Pretovio" (tal vez un anagrama de Pablo Restivo); el texto Partículas de la lengua guarani de 1697; una Breve noticia de la lengua guaraní de 1718 escrita por Restivo y antecedente de su Arte impreso en 1724; un Compendio de los vocablos más usados en la lengua española y guaraní, sacado del vocabulario del $P$. Blas Pretovio de 1729; y un Vocabulario de todos los verbos usados en la lengua guarani con las partículas al fin también de 1729 (Melià, 1992, pp. 82-95). Ahora bien, de todo lo antedicho se infiere precisamente que existió una amplia producción lingüística con posterioridad (y también anterioridad) a Antonio Ruiz de Montoya. Variados actores contribuyeron a la cultura textual en este idioma; el manuscrito Phrases Selectas es una de las materializaciones concretas de este fenómeno.

\section{Un manuscrito titulado Phrases Selectas}

Hoy en día se conservan dos ejemplares del manuscrito Phrases Selectas. Uno se encuentra en el Museo Mitre (Buenos Aires) (véase Figura 1). El otro pertenece a la Colección Peña del Museo Udaondo (Luján). Aunque son similares, los dos ejemplares no son exactamente iguales (Chamorro, 2014). Aquí nos concentraremos en el primer ejemplar mencionado ${ }^{19}$. En sus primeras páginas, este contiene algunas inscripciones manuscritas de época posterior al siglo XVIII, que aquí dejaremos de lado $^{20}$. Los manuscritos elaborados en el contexto de las misiones jesuíticas de guaraníes solían imitar los caracteres de imprenta. En el caso de Phrases Selectas, esto es así especialmente con respecto a su portada, que podría transcribirse de la siguiente manera:

PHRASES / SELECTAS, / Y MODOS DE HABLAR /
ESCOGIDOS / Y USADOS EN LA LENGVA GVARÂNI /
Sacados del Theforo efcondido que / compufo el venerable /
PADRE ANTONIO RUIZ / de nueftra Compañia de / IESVS /
PARA CONSVUELO Y ALIVIO / DE LOS FERVOROSOS MI /
SSIONEROS / principiantes en la dicha / lengua.

La portada manuscrita no provee datos acerca del momento y lugar de producción del texto, así como tampoco de la persona que se encargó de "sacar" y "escoger" las "phrases selectas" a partir del Tesoro de la lengua guaraní (1639) de Ruiz de Montoya. Con caligrafías diferentes, que ya no imitan los caracteres de imprenta, se pueden reconocer dos marginalia en esta portada. En la sección superior se escribió: "Es del Pe. Ramila". Parece tratarse de una alusión a la propiedad del manuscrito por

${ }^{19}$ Buenos Aires. Museo Mitre, Biblioteca Americana, 14-4-41, Phrases Selectas... En los distintos catálogos de la institución, el texto aparece atribuido a Antonio Ruiz de Montoya.

${ }^{20}$ En sentido estricto, una de las primeras inscripciones (tachada) parece referir a un jesuita (quizás anterior a la expulsión): "P. Diego de Barjas". No obstante, no hemos podido identificar a esta figura. 
Vega. La posible autoría del manuscrito anónimo Phrases Selectas, entre el uno y el múltiple (Misiones Jesuíticas de...

parte del misionero jesuita Pedro de Rámila ${ }^{21}$. En la sección inferior de la portada se lee, en una letra aparentemente diferente a la del marginalia anterior, "de S. Xavier". Seguramente se trate de una alusión a la reducción en que se conservaba el manuscrito. Como veremos, San Francisco Javier también parece ser el lugar en que el libro se produjo. Un catálogo de los libros de esta reducción elaborado en la década de 1770 refiere a la existencia de dos vocabularios manuscritos atribuidos a Ruiz de Montoya ${ }^{22}$. Es posible que uno de estos manuscritos fuese el ejemplar de Phrases Selectas del Museo Mitre.

Figura 1. Portada de Phrases Selectas (Museo Mitre).

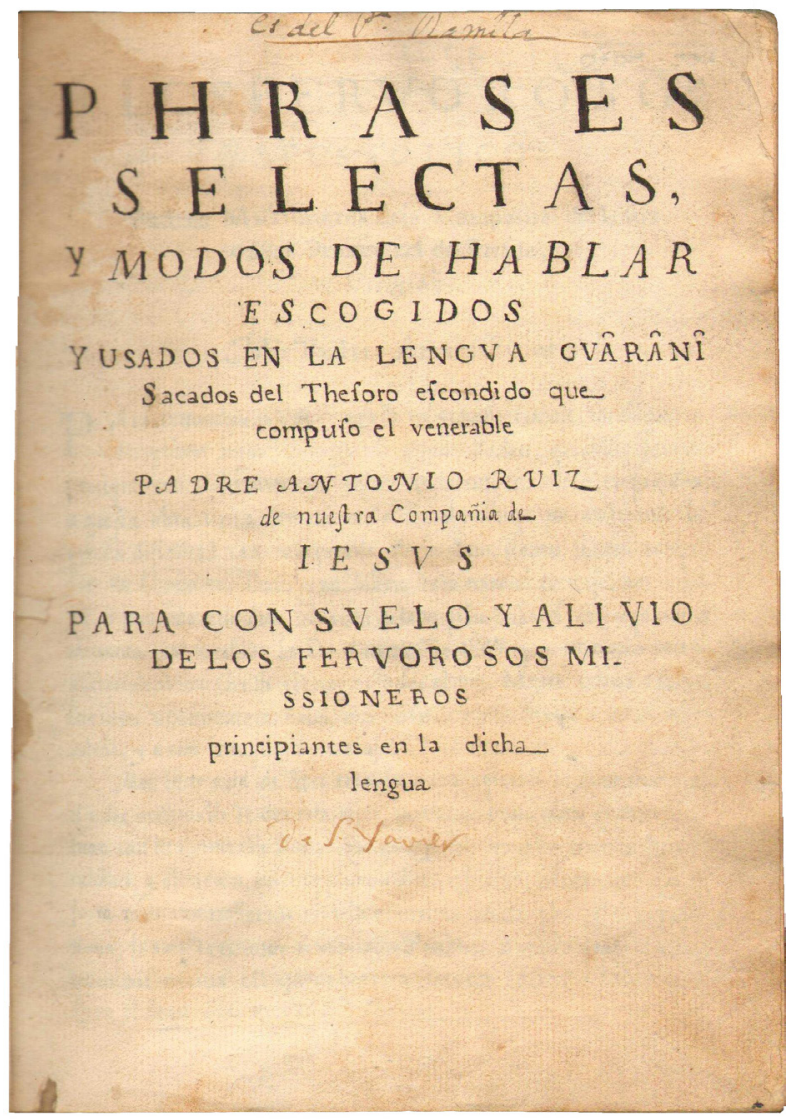

${ }^{21}$ Pedro de Rámila nació en 1678 en Buenos Aires y falleció en la reducción de Nuestra Señora de Fe (departamento de Misiones, Paraguay) en 1748 (Storni, 1980, p. 232).

22 Además se consignan dos "artes" (gramáticas) también atribuidas a Ruiz de Montoya y un catecismo escrito por Nicolás Yapuguay. Todos ellos manuscritos. Buenos Aires. AGN, Sala IX, 07-01-01, "Catalogo delos Libros de Este Pueblo de $\mathrm{S}^{\mathrm{n}}$. Fran ${ }^{\mathrm{co}}$. Xavier Escristos [sic] por Varios Autores Jesuitas" (sin foliación). 
El manuscrito posee, en total, 659 páginas. Está conformado por dos paratextos iniciales (una dedicatoria a los misioneros jesuitas y un prólogo al lector), el cuerpo principal del texto (el diccionario castellano-guaraní, organizado alfabéticamente), un índice posterior y, finalmente, una suerte de apéndice en que se incluye un listado de palabras no incluidas en el diccionario anterior. Consiste en una conversión del Tesoro de Ruiz de Montoya (diccionario guaraní-castellano) en un diccionario castellano-guaraní y, también, en una actualización y adaptación de dicho texto a partir de la consideración de la especificidad dialectal del guaraní de las reducciones de San Francisco Javier y Santa María la Mayor, ambas muy cercanas entre sí y ubicadas a la vera del río Uruguay. Este objetivo es explicitado en los paratextos iniciales. Además, se menciona también como un motivo para la producción del diccionario "la dificultad casi insuperable que los Principiantes sienten en aprender un Idioma tan extraño y tan distinto de su natural lenguaje", para lo cual se elabora un Tesoro reducido "a más fácil método" ${ }^{23}$. En el prólogo al lector se indica que muchos vocablos y modos de hablar contenidos en el Tesoro "se han anticuado y hecho casi inteligibles [sic, por ininteligibles]". A su vez, quien redacta este paratexto asegura que él mismo fue "uno de los que, al principio, no hacían caso de dicho Tesoro" por "haber oído que era tiempo perdido el leerle" o "porque leyendo algunos párrafos a los naturales no me entendían". No obstante, aclara que, finalmente, decidió emprender el estudio del libro de Ruiz de Montoya, a partir de lo cual pretendió "sacarle en limpio"24.

La autoría de este manuscrito ha sido debatida por distintos investigadores. En el siglo XIX, el libro estuvo en posesión de Pedro De Angelis, quien lo registró en el apéndice de su Colección de obras impresas y manuscritas (Obermeier, 2017) sin mayores indicaciones. Posteriormente pasó a formar parte de la colección de Bartolomé Mitre, colección que se convirtió en el acervo del actual Museo Mitre tras su muerte. Un catálogo temprano de esta institución lo atribuye únicamente a Ruiz de Montoya, desde luego a partir de la información de portada (Lenguas Americanas. Catálogo Ilustrado de La Sección X de La Biblioteca, 1912, pp. 151-152). Sin desconocer la relevancia del texto de base de Ruiz de Montoya, mucho tiempo después Bartomeu Melià, en su tesis doctoral defendida en 1969 y publicada en 2003, consideró que el libro había sido escrito por Pablo Restivo ${ }^{25}$. El razonamiento para postular esta autoría, no necesariamente explicitado por Melià, es el siguiente. Existe una serie de manuscritos lingüísticos elaborados en torno a 1696 que contienen una auto-atribución autoral a "Blas Pretovio", un personaje desconocido cuyo nombre puede ser perfectamente el

${ }^{23}$ Buenos Aires. Museo Mitre, Biblioteca Americana, 14-4-41, Phrases Selectas..., "A los fervorosos y apostolicos Padres Missioneros...", sin paginación.

${ }^{24}$ Buenos Aires. Museo Mitre, Biblioteca Americana, 14-4-41, Phrases Selectas..., "Amigo en Christo y benevolo lector", sin paginación.

${ }^{25}$ Pablo Restivo nació en Mazzarino (Caltanisetta, Italia) en 1658, arribó a Buenos Aires en 1691 y falleció en la reducción de Candelaria (provincia de Misiones, Argentina) en 1740. Fue superior de las misiones de guaraníes entre 1718 y 1720 (Storni 1980:236). Restivo escribió tres libros impresos en las reducciones: Manuale ad usum Patrum Soceitatis Iesu (1721), Vocabulario de la lengua guarani (1722) y Arte de la lengua guarani (1724). Además, colaboró en la publicación de Explicación de el catechismo en lengua guaraní (1724) y de los Sermones y exemplos en lengua guarani (1727), escritos por Nicolás Yapuguay. 
Vega. La posible autoría del manuscrito anónimo Phrases Selectas, entre el uno y el múltiple (Misiones Jesuíticas de...

anagrama de "Pablo Restivo". El manuscrito Phrases Selectas, que carece de esta autoatribución, es aproximadamente contemporáneo a los otros manuscritos mencionados, y por lo tanto podría ser considerado un texto hermano de estos. De este modo, Blas Pretovio (bajo cuyo nombre se escondería Restivo) sería el autor de los manuscritos a su nombre y también de Phrases Selectas. Sin embargo, en el caso puntual de este último diccionario, como lo han puesto de relieve distintos investigadores, existe un problema cronológico: uno de los paratextos del libro está firmado en 1687, mientras que el italiano Restivo desembarcó en América recién cuatro años más tarde (Storni, 1980, p. 236). Poco convincentemente, Melià (2003) salvó esta dificultad indicando que la fecha de 1687 sería un error del copista.

Más recientemente, Chamorro incluyó comentarios sobre la autoría del manuscrito en un artículo que analiza en general el contenido del diccionario. Indicó el problema cronológico de la interpretación de Melià y llamó la atención sobre la ausencia de auto-atribución autoral a Blas Pretovio. No obstante, señaló respecto de la autoría que "mientras no tengamos más datos, nos parece prudente mantener las Phrases Selectas como de autoría anónima" (Chamorro, 2014, p. 5). Por su parte, Obermeier postuló la posibilidad, también en un trabajo reciente, de que este manuscrito haya sido escrito por el jesuita Pedro de Rámila (Obermeier, 2017, pp. 12-13). Esto obedece al marginalia relativo a este misionero en la portada del manuscrito. Aunque ciertamente es razonable la consideración de Obermeier de que no era común que se "marcase" la posesión "privada" de libros en las misiones de guaraníes, la atribución posee también un problema cronológico similar al de Restivo. Pedro de Rámila nació en noviembre de 1678; en la fecha en que aparece firmado uno de los paratextos del libro (septiembre de 1687), tenía tan solo ocho años de edad. Además, como veremos a continuación, el autor de este paratexto declara no ser hispano-parlante de nacimiento; Rámila, sin embargo, nació en Buenos Aires (Storni, 1980, p. 232). A pesar de esto, juzgamos que Obermeier acierta en no reducir toda la producción lingüística sobre el guaraní a las figuras de Ruiz de Montoya y Restivo (Obermeier y Cerno, 2013, pp. 43-44); este es un punto sobre el que volveremos hacia al final del trabajo.

\section{Reconstrucción de indicios relativos al jesuita organizador del manuscrito}

Tanto en la dedicatoria a los misioneros como en el prólogo al lector existe información clara sobre el contexto a partir del cual alguien - el organizador principal del material lingüístico compilado en Phrases Selectas - "habla". Los datos que pueden recopilarse son los siguientes: en primer lugar, la dedicatoria a los misioneros está firmada el 27 de septiembre de 1687; en segundo lugar, esta misma dedicatoria fue escrita en la reducción de San Francisco Javier. Debido a los comentarios sobre la peculiaridad dialectal de este pueblo y de la vecina reducción de Santa María la Mayor, es probable que el autor de los paratextos contase con experiencia misional (más o menos prolongada) en uno de los pueblos o quizás en ambos. Eventualmente, podría llegar a tratarse de alguien vinculado a reducciones cercanas a las dos mencionadas, 
como Concepción y San Nicolás ${ }^{26}$. Esta peculiaridad dialectal, documentada en este manuscrito, obedece al hecho de que - aunque en todos los pueblos se hablase guaraní- con el paso del tiempo surgieron variedades lingüísticas entre distintos pueblos, variedades que los jesuitas comenzaron a valorar sólo tardíamente (Obermeier y Cerno, 2013). En tercer lugar, en el prólogo al lector el autor declara no ser ni hispanoparlante ni guaraní-parlante nativo. Se infiere entonces que no nació ni en la Península Ibérica ni en los territorios hispánicos de América. De la dedicatoria a los misioneros se entiende que es indudablemente un jesuita.

Tiempo, espacio, conocimientos lingüísticos y lugar de nacimiento de este jesuita son, por lo tanto, los datos que poseemos o que podemos inferir. Creemos que la posibilidad de establecer correlaciones entre estos datos es la clave para identificar a este jesuita puntual. Para esto pueden resultar útiles los catálogos públicos y secretos de la provincia del Paraguay de la Compañía de Jesús, actualmente conservados en el Archivum Romanum Societatis Iesu en Roma. Los catálogos contienen información personal biográfica de cada uno de los jesuitas, incluyendo una suerte de "puntaje" en determinadas habilidades y aptitudes como predicación, estudios, ingenio, juicio, experiencia, complexión, etc. (Maldavsky, 2012). Pero, además, en algunas ocasiones incluyen también información sobre la institución a la que estaban asignados todos los jesuitas de una determinada provincia. Dado un año puntual, es posible entonces que podamos conocer quiénes eran los misioneros encargados de cada una de las reducciones de guaraníes. Contamos con información completa, por ejemplo, para los años 1678, 1681, 1686, 1687 y 1689. Después de 1689 no existen nuevos datos completos hasta 1710. Considerando las dos reducciones mencionadas en el libro (San Francisco Javier y Santa María la Mayor) y los dos pueblos más cercanos (Concepción y San Nicolás) en los años aludidos, obtenemos el resultado que se plasma en la Tabla 1.

Como se puede observar, en 1687 sólo había dos jesuitas no hispano-parlantes de nacimiento en esta constelación de reducciones. Ambos estaban asignados a la reducción de San Francisco Javier: José Coco y Tomás Brown. Todos los demás misioneros consignados en la tabla para este año nacieron en territorio actualmente español. Además, se observa que, a lo largo de estos años, no hubo otros jesuitas extranjeros que contasen con experiencia misional en los pueblos mencionados en el libro. La excepción la constituye el italiano Francisco María Bensonio, un jesuita experimentado que estaba en territorio americano desde $1674{ }^{27}$ y se encontraba en Santa María la Mayor en 1686. No obstante, no hay registros de que haya pasado por San Francisco Javier. De modo que las opciones restantes son José Coco y Tomás Brown. Brown, irlandés de nacimiento, sin duda había aprendido el castellano y el guaraní como

${ }^{26}$ Desde luego, el conocimiento lingüístico que en el libro se manifiesta sobre la peculiaridad dialectal de San Francisco Javier y de Santa María la Mayor refuta la posibilidad de que el libro haya sido firmado por un jesuita que se encontraba de paso en el primero de estos pueblos en septiembre de 1687.

${ }^{27}$ Francisco María Bensonio nació en Génova (Italia) en 1646, arribó a Buenos Aires en 1674 y falleció la reducción de Santa María la Mayor (provincia de Misiones, Argentina) en 1717 (Storni, 1980, pp. 36-37). En 1687 estaba asignado a la reducción de Candelaria. Roma. ARSI, Paraq. 4, "Catalogus annus Prouinciae Paraquariae anni 1687”, f. 385r. 
Vega. La posible autoría del manuscrito anónimo Phrases Selectas, entre el uno y el múltiple (Misiones Jesuíticas de...

lenguas no maternas ${ }^{28}$. Sin embargo, sólo llegó a Buenos Aires en mayo de 1685 y a las reducciones de guaraníes en $1687^{29}$. Resulta imposible que en tan poco tiempo se haya convertido en un especialista de la lengua guarani ${ }^{30}$. El único misionero que figura en la tabla y cumple los requisitos de datos del manuscrito Phrases Selectas es José Coco, también denominado José Tolo o Tolu. Este jesuita nació en Posadas (Cerdeña, Italia) en 1643, ingresó a la Compañía de Jesús en 1664 en Cerdeña y se convirtió en sacerdote en 1673, estando ya en Sevilla. Desembarcó en Buenos Aires en marzo de 1674 (Storni, 1980, p. 66) y concluyó sus estudios en Córdoba (Machoni, 1732, p. 234). Dentro de las misiones de guaraníes, el primer pueblo en el que lo encontramos es San Nicolás en 1678. En el espacio de las misiones de guaraníes, según Machoni, "se aplicó con tesón a aprender la lengua Guaraní, que supo con perfección" (Machoni, 1732, p. 234; el subrayado nos pertenece). Estuvo en San Nicolás hasta, por lo menos, 1681. Se trata de una reducción ubicada a menos de 40 kilómetros de San Francisco Javier (véase la Figura 2). Desconocemos el paradero de Coco entre 1681 y 1686. Machoni informa que durante algún tiempo estuvo en la reducción de Santo Tomé (Machoni, 1732, p. 236). Si se trata, como creemos, del organizador principal de Phrases Selectas y actualizador del Tesoro de Ruiz de Montoya, es probable que haya estado encargado de San Francisco Javier desde antes de 1686. Su relación cercana con esta reducción se confirma por un documento de 1699, escrito desde Tarija, en que defiende los derechos de este pueblo en un pleito por tierras con la reducción de Concepción ${ }^{31}$.

${ }^{28}$ Tomás Brown nació en Waterford (Munster, Irlanda) en 1655, arribó a Buenos Aires en 1685 y falleció en la reducción de Santos Apóstoles (provincia de Misiones, Argentina) en 1717 (Storni, 1980, p. 44).

${ }^{29}$ En el catálogo de 1686 no se encuentra en las reducciones. Roma. ARSI, Paraq. 4, "Catalogus annus Prouinciae Paraquariae anni 1686", f. 380v.

${ }^{30}$ Un documento conservado en la Biblioteca Nacional de Rio de Janeiro incluye algunos datos diferentes a los consignados en la Tabla 1 para la reducción de San Francisco Javier. Se enlistan allí los sacerdotes encargados de este pueblo: en 1679, Alonso Delgado; en 1681, José Coco; en 1687, Antonio de Acevedo; en 1688, nuevamente José Coco; y en 1690 José Mazo. Es posible que la fecha de cada año corresponda a una diferente de aquella sobre la que se elaboraban los catálogos. El documento no indica que Coco no estuviera en San Francisco Javier en 1687, sino que no era el sacerdote encargado de la reducción, aunque lo había sido antes y lo sería después. Machoni aludió efectivamente a un confuso episodio en que una serie de calumnias afectaron a Coco, de modo que le fue sustraído el rol de encargado de una reducción (que Machoni no menciona), hasta que este fue restituido por el prepósito general Carlos de Noyelle (1682-1686). Rio de Janeiro. Biblioteca Nacional do Brasil. Coleçao Pedro De Angelis, I-294-70. "Títulos del derecho que tiene el pueblo de San Francisco Xavier á los montes y tierras de aquel partido", f. 6r.

${ }^{31}$ Rio de Janeiro. Biblioteca Nacional do Brasil. Coleçao Pedro De Angelis, Manuscrito 508-21, número 518. "Títulos de las tierras que pertenecen al pueblo de San Francisco Xavier". Aunque es un tema que aún no se encuentra investigado, pareciera que algunos jesuitas mantenían cierto apego a reducciones en donde habían vivido un tiempo prolongado, reducciones a las que solían apoyar en los contextos de disputas territoriales o fronterizas. Agradezco a Kazuhisa Takeda el haberme informado sobre este documento. 
Tabla 1. Jesuitas con su correspondiente nacionalidad asignados a las reducciones de San Francisco Javier, Santa María la Mayor, Concepción y San Nicolás entre 1678 y $1689^{32}$.

\begin{tabular}{|c|c|c|c|c|}
\hline Año & San Francisco Javier & $\begin{array}{c}\text { Santa María la } \\
\text { Mayor } \\
\end{array}$ & Concepción & San Nicolás \\
\hline \multirow[b]{2}{*}{1678} & $\begin{array}{c}\text { Fernando de Santa Cruz } \\
\text { (Argentina) }\end{array}$ & $\begin{array}{l}\text { Fernando García } \\
\text { (España) }\end{array}$ & $\begin{array}{l}\text { Diego Suárez } \\
\text { (Argentina) }\end{array}$ & $\begin{array}{l}\text { Alonso Delgado } \\
\text { (España) }\end{array}$ \\
\hline & $\begin{array}{l}\text { Andrés Gallego } \\
\text { (España) }\end{array}$ & $\begin{array}{c}\text { Miguel Ángel Serra } \\
\text { (Italia) }\end{array}$ & $\begin{array}{c}\text { Francisco de } \\
\text { Castañeda } \\
\text { (Argentina) }\end{array}$ & $\begin{array}{l}\text { José Coco } \\
\text { (Italia) }\end{array}$ \\
\hline \multirow{3}{*}{1679} & $\begin{array}{l}\text { Alonso Delgado } \\
\text { (España) }\end{array}$ & $\begin{array}{l}\text { Fernando García } \\
\text { (España) }\end{array}$ & $\begin{array}{l}\text { Diego Suárez } \\
\text { (Argentina) }\end{array}$ & $\begin{array}{l}\text { Leandro Saliñas } \\
\text { (España) }\end{array}$ \\
\hline & $\begin{array}{l}\text { Juan Ramos } \\
\text { (España) }\end{array}$ & $\begin{array}{l}\text { Jerónimo Delfín } \\
\text { (España) }\end{array}$ & $\begin{array}{l}\text { Andrés Gallego } \\
\text { (España) }\end{array}$ & $\begin{array}{l}\text { Francisco Jiménez } \\
\text { (España) }\end{array}$ \\
\hline & - & - & $\begin{array}{l}\text { José Saravia } \\
\text { (España) }\end{array}$ & $\begin{array}{l}\text { Domingo Torres } \\
\text { (España) }\end{array}$ \\
\hline \multirow{3}{*}{1681} & $\begin{array}{l}\text { Alonso Delgado } \\
\text { (España) }\end{array}$ & $\begin{array}{c}\text { Francisco María } \\
\text { Bensonio } \\
\text { (Italia) }\end{array}$ & $\begin{array}{c}\text { Fernando de Santa } \\
\text { Cruz } \\
\text { (Argentina) }\end{array}$ & $\begin{array}{c}\text { Cristóbal Altamirano } \\
\text { (Argentina) }\end{array}$ \\
\hline & $\begin{array}{l}\text { Jacinto Márquez } \\
\text { (España) }\end{array}$ & $\begin{array}{l}\text { Tomás Saavedra } \\
\text { (España) }\end{array}$ & $\begin{array}{l}\text { Francisco Jiménez } \\
\text { (España) }\end{array}$ & $\begin{array}{l}\text { José Coco } \\
\text { (Italia) }\end{array}$ \\
\hline & - & - & $\begin{array}{l}\text { Jerónimo Delfín } \\
\text { (España) }\end{array}$ & - \\
\hline \multirow{4}{*}{1686} & $\begin{array}{l}\text { José Coco } \\
\text { (Italia) }\end{array}$ & $\begin{array}{l}\text { Alonso Delgado } \\
\text { (España) }\end{array}$ & $\begin{array}{l}\text { José Serrano } \\
\text { (España) }\end{array}$ & $\begin{array}{l}\text { Domingo Rodiles } \\
\text { (España) }\end{array}$ \\
\hline & $\begin{array}{l}\text { Pedro de Medina } \\
\quad \text { (España) }\end{array}$ & $\begin{array}{l}\text { Antonio de Acevedo } \\
\text { (España) }\end{array}$ & $\begin{array}{c}\text { Miguel Fernández } \\
\text { (Paraguay) }\end{array}$ & $\begin{array}{l}\text { Francisco Rojas } \\
\text { (España) }\end{array}$ \\
\hline & - & - & - & $\begin{array}{c}\text { Cristóbal Altamirano } \\
\text { (Argentina) }\end{array}$ \\
\hline & - & - & - & $\begin{array}{l}\text { Domingo Torres } \\
\text { (España) }\end{array}$ \\
\hline \multirow{3}{*}{1687} & $\begin{array}{l}\text { José Coco } \\
\text { (Italia) }\end{array}$ & $\begin{array}{l}\text { Tomás Saavedra } \\
\text { (España) }\end{array}$ & $\begin{array}{l}\text { José Serrano } \\
\text { (España) }\end{array}$ & $\begin{array}{l}\text { Alonso Delgado } \\
\text { (España) }\end{array}$ \\
\hline & $\begin{array}{l}\text { José Mazo } \\
\text { (España) }\end{array}$ & $\begin{array}{l}\text { Bernardo de Vega } \\
\text { (España) }\end{array}$ & $\begin{array}{l}\text { Antonio del Río } \\
\text { (España) }\end{array}$ & $\begin{array}{c}\text { José Pablo Castañeda } \\
\text { (España) }\end{array}$ \\
\hline & $\begin{array}{l}\text { Tomás Brown } \\
\text { (Irlanda) }\end{array}$ & - & - & - \\
\hline
\end{tabular}

${ }^{32}$ Se consignan los lugares de nacimiento a partir de los países actualmente existentes. Debe recordarse que el uso de esta información en este trabajo está en relación con los conocimientos lingüísticos del jesuita analizado. La información de esta tabla se elabora a partir de: Roma. ARSI, Paraq. 4-2, "Catalogus annuus Prouinciae Paraquariae anni 1686", f. 380v y "Catalogus annuus Prouinciae Paraquariae anni 1687", f. 385r; Paraq. 7, "Paraguay Catalogo Breve", ff. 22r-v, "Catalogus Prouintiae Paraquariae anno 1679", ff. 24r-v, "Catalogus annuus Prouinciae Paraquariae Anno 1681", ff. 26r-v y "Catalogus annuus Prou. Paraquariae anni 1689”, ff. 28v y 30v. 
Vega. La posible autoría del manuscrito anónimo Phrases Selectas, entre el uno y el múltiple (Misiones Jesuíticas de...

\begin{tabular}{ccccc}
\hline \multirow{2}{*}{$\begin{array}{c}\text { José Mazo } \\
\text { (España) }\end{array}$} & $\begin{array}{c}\text { Domingo Rodiles } \\
\text { (España) }\end{array}$ & $\begin{array}{c}\text { Francisco María } \\
\text { Bensonio } \\
\text { (Italia) }\end{array}$ & $\begin{array}{c}\text { José Pablo Castañeda } \\
\text { (España) }\end{array}$ \\
\cline { 2 - 5 } & $\begin{array}{c}\text { Pedro de Orduña } \\
\text { (España) }\end{array}$ & $\begin{array}{c}\text { Francisco Sánchez* } \\
\text { (España) }\end{array}$ & $\begin{array}{c}\text { Tomás Brown } \\
\text { (Irlanda) }\end{array}$ & $\begin{array}{c}\text { Antonio Salgado } \\
\text { (España) }\end{array}$ \\
\hline & $\begin{array}{c}\text { Diego Vidal } \\
\text { (España) }\end{array}$ & - & - \\
\hline
\end{tabular}

Figura 2. Ubicación de las reducciones de San Francisco Javier, Santa María la Mayor, Concepción y San Nicolás en el marco de un mapa actual.

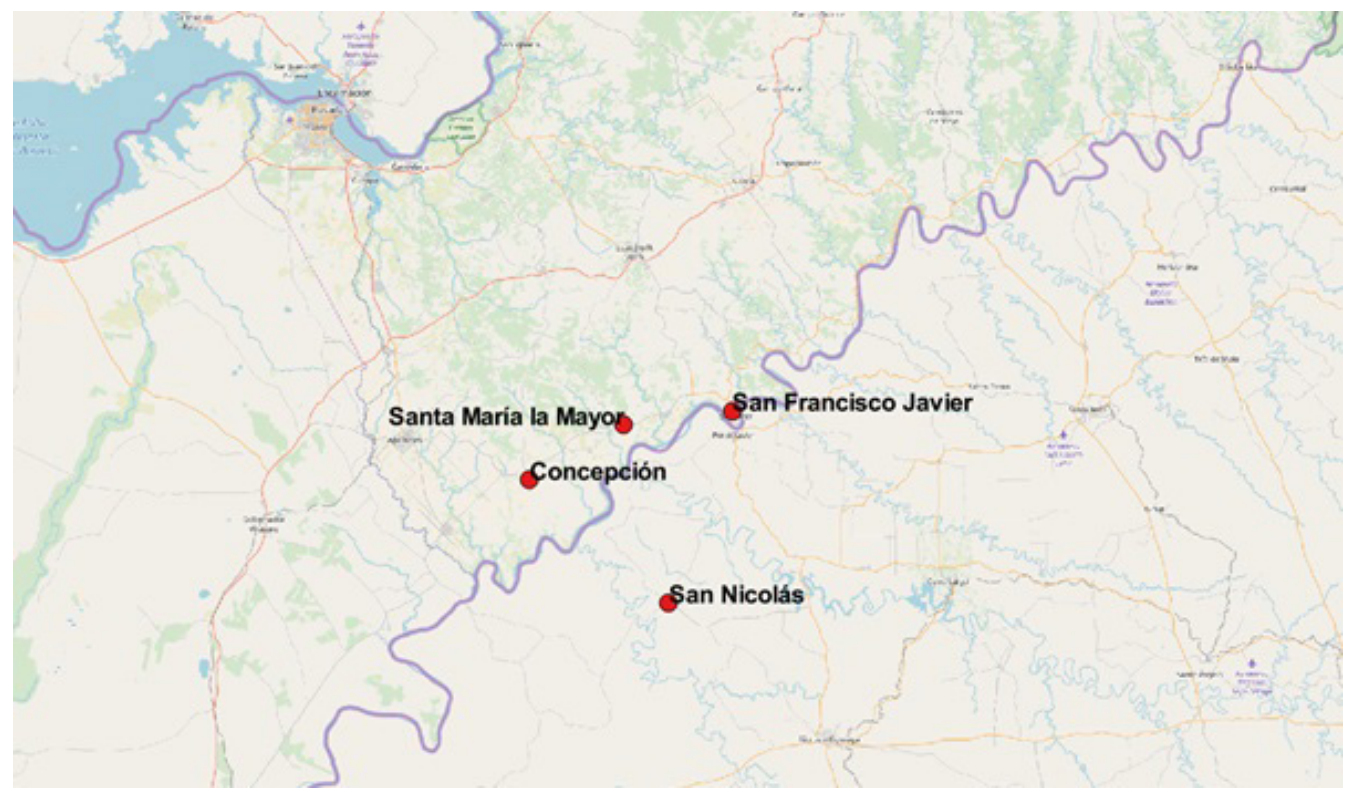

Ahora bien, si esto es así, ¿por qué José Coco manifiesta conocimiento de las especificidades lingüísticas de Santa María la Mayor? Aunque no debería rechazarse la posibilidad de que hubiera estado asignado a esta última reducción entre 1681 y 1686, existen también explicaciones alternativas. En primer lugar, como se observa en la Figura 2, San Francisco Javier y Santa María la Mayor son pueblos muy cercanos, únicamente separados por 20 kilómetros. No resulta improbable que por razones operativas conociese la especificidad lingüística de este territorio. En segundo lugar, no era algo fuera de lo común que los misioneros realizasen algunas actividades en pueblos vecinos. Un libro de preceptos de las reducciones de guaraníes — que contiene las normas que seguían los jesuitas - indica que los misioneros debían mudarse a un pueblo vecino para la realización de los ejercicios espirituales ${ }^{33}$. Por su parte, en 1747 José Cardiel ${ }^{34}$ explicó en su relación

33 Buenos Aires. AGN. Sala VII, Colección Biblioteca Nacional-140, f. 10r.

34 José Cardiel nació en Laguardia (Álava, España) en 1704, arribó a Buenos Aires en 1729 y falleció en 
sobre las misiones de guaraníes que los sacerdotes debían trasladarse a otro pueblo para que los indios se confesasen con más libertad ${ }^{35}$. Una afirmación en el prólogo de Phrases Selectas podría interpretarse en un sentido similar:

"No digo esto (Benévolo lector) sin alguna experiencia, porque en San Javier se usan modos de hablar tan particulares, que valiéndome yo de ellos en Santa María [la Mayor], y en otros pueblos, no me entendían, y fue necesario mudar de rumbo, y buscar otros usuales en aquel pueblo; lo mismo suele acontecer en los confesionarios, donde se oyen particulares modos propios de aquel pueblo, y no de otros"36.

Como se ha indicado, los catálogos de la Compañía de Jesús proveen algunos datos sobre conocimientos y habilidades de los jesuitas. Esta información prácticamente no ha sido utilizada para la investigación de la provincia del Paraguay, aunque existen análisis con estos datos para otras provincias (Castelnau-L'Estoile, 2000 y Maldavsky, 2012). En el caso particular de José Coco, resulta interesante señalar que sus aptitudes en 1687 (año de escritura de Phrases Selectas) — como sus estudios, su ingenio, su juicio, su experiencia, su habilidad con las letras y la escritura y su talento para la evangelización - son casi exactamente iguales a los que tenía uno de los lingüistas jesuitas por excelencia, Pablo Restivo, diez años más tarde, precisamente en el contexto de la escritura de los manuscritos atribuidos a "Blas Pretovio". Las diferencias entre los dos misioneros son muy escasas: en 1697, Restivo es un poco más joven que Coco diez años antes, y también existe una leve diferencia en cuanto a las tareas que cada uno ejerció. Ambos se desempeñaron como lectores de gramática en algún colegio: cuatro años en el caso de Restivo y una cantidad de tiempo indeterminada en el caso de Coco. La gramática, desde luego, es un conocimiento esencial para la escritura de una obra lingüística. La comparación global puede ser observada en la Tabla 2.

Tabla 2. Comparación de las habilidades, aptitudes y educación de José Coco y Pablo Restivo en el momento de su presunta producción lingüística37.

\begin{tabular}{lll}
\hline Año & 1687 & 1697 \\
\hline Nombre & P. José de Tollu & P. Pablo Restivo \\
\hline Patria & Posada en Cerdeña & Mazzari en Sicilia \\
\hline Edad & Nacido en 21 Noviembre & Nacido en 30 Agisti 1658 \\
\hline Salud & 1643 & Íntegra \\
\hline Ingreso a la Compañía & Íntegra & 20 Mayo 1664 \\
\hline
\end{tabular}

Faenza (Ravena, Italia) en 1781 (Storni, 1980, p. 52).

35 "Por las Cuaresmas se mudan todos los Curas, yendo cada uno por 8 días a otro pueblo a hacer misión, para que así, con más libertad puedan sus feligreses confesarse con otro" (Furlong, 1953, p. 136).

${ }^{36}$ Buenos Aires. Museo Mitre, Biblioteca Americana, 14-4-41, Phrases Selectas..., "Amigo en Christo y benevolo lector", sin paginación.

37 “Catalogus Prou. Paraquariae anni 1687”, ff. 366r y 377v. 
Vega. La posible autoría del manuscrito anónimo Phrases Selectas, entre el uno y el múltiple (Misiones Jesuíticas de...

\begin{tabular}{lll}
\hline Estudios [años] & Filosofía 3; Teología 4 & Filosofía 3; Teología 4 \\
\hline Ministerios y tareas & $\begin{array}{l}\text { Lector de gramática. Operario } \\
\text { de indios en misiones durante } \\
11 \text { años }\end{array}$ & $\begin{array}{l}\text { Lector de gramática durante 4 } \\
\text { años. Operario por 8 años de } \\
\text { españoles e indios. Misionero } \\
\text { durante 6 años. }\end{array}$ \\
\hline Grado en letras & - & - \\
\hline Grado en la Compañía & Profeso de 4 votos desde 15 & $\begin{array}{l}\text { Profeso de 4 votos desde 15 } \\
\text { Agosto 1695 }\end{array}$ \\
\hline Ingenio & Agosto 1682 & Bueno \\
\hline Juicio & Bueno & Bueno \\
\hline Prudencia & Bueno & Suficiente \\
\hline Experiencia & Suficiente & Suficiente \\
\hline Progreso en letras & Suficiente & Bueno \\
\hline
\end{tabular}

Lo que esta comparación permite demostrar es que en 1687 José Coco contaba con las habilidades que más tarde caracterizarían al mayor conocedor del guaraní en la época. Es poca la información restante que tenemos sobre este personaje. Además de los catálogos, existen sobre él tres textos biográficos, contenidos en la Relación historial de las misiones de los indios chiquitos de Juan Patricio Fernández (1726), en Las siete estrellas de la mano de Jesús de Antonio Machoni (1732) y en la carta anua de 1714-1720. Sabemos que, poco tiempo después de la escritura de Phrases Selectas, fue trasladado al colegio de Santa Fe para desempeñarse como procurador; luego, fue destinado a la fundación del colegio de Tarija (Machoni, 1732, p. 237). Según Machoni, desde allí fomentó las misiones a los chiriguanos hasta que pasó a ocuparse personalmente de ellas. No resulta extraño que un especialista en la lengua guaraní fuese destinado a estos indígenas: los chiriguanos, pueblo que habitaba cerca de las ciudades de Salta y Tarija, hablaban la lengua guaraní. También Pablo Restivo en 1715 y otros cuatro jesuitas considerados "lenguaraces" del guaraní en 1732 (Rafael Jiménez, Julián Lizardi, Ignacio Chomé y José Pons) fueron destinados a evangelizar entre los chiriguanos (Salinas y Folkenand, 2017, p. 270). Machoni explicita que Coco "aquí tenía vencida essa dificultad [del idioma], por hablar los Chiriguanás la lengua de los Guaraníes, en que era perito el Siervo de Dios" (Machoni, 1732, p. 238; el subrayado nos pertenece). En los catálogos, Coco aparece asignado a las misiones de chiriguanos en 1692 y $1693^{38}$; pero según Machoni estaba en ellas desde 1691. A partir de 1695 y hasta 1697, los catálogos indican que Coco regresó al colegio de Tarija ${ }^{39}$. En 1699 fue designado superior de las misiones de indios chiquitanos (Machoni, 1732, p. 247). Mantuvo este puesto hasta 1703 (Storni, 1980, p. 66) ${ }^{40}$. Nunca más abandonó dicho territorio y falleció en el mismo en 1717. Al poco tiempo se escribía su obituario

\footnotetext{
${ }^{38}$ Roma. ARSI, Paraq. 7, "Catalogus Annuus Prouinciae Paraquariae 1692”, f. 34v y "Catalogus Annuus Prouinciae Paraquariae Anno 1693", f. 38v.

${ }^{39}$ Roma. ARSI, Paraq. 7, “Catalogus Annuus Prouinciae Paraquariae Anno 1695”, f. 42r y "Catalogus Annuus Prouinciae Paraquariae Anno 1697”, f. 44v. Existe además una referencia marginal a Coco en una alusión a Tarija en la carta anua de 1689-1700 escrita por Ignacio Frías (Salinas y Folkenand 2015, p. 245).

${ }^{40}$ Roma. ARSI, Paraq. 6, "Catalogus Publicus Prouinciae Paraquariae Anno 1703", f. 19r.
} 
contenido en la carta anua de 1714-1720. A pesar de las dos referencias del libro de Machoni a sus conocimientos de guaraní, en este nuevo texto no existen alusiones al respecto. Al fin y al cabo, en 1717, cuando murió, ya habían pasado unos treinta años desde que el misionero había abandonado las reducciones de guaraníes

"Mientras tanto acabó su vida laboriosa en el pueblo de San Rafael el padre José Tolú, profeso de cuatro votos, a los [f. 372v] 74 años de edad y 53 de vida religiosa. Era natural de Cerdeña sujeto excelente en todo sentido, muy amable y grave, poseyendo ambas cualidades en tal harmonía que era difícil decir, si uno tenía que amar en él más al venerable anciano, o al buen compañero. Era misionero entre los indios del Paraná y Uruguay, entre los chiriguanos y ante todo entre los chiquitos. Es imposible enumerar los trabajos sufridos en estas empresas apostólicas. Siendo superior de las misiones de chiquitos mostró admirables dotes de gobierno y dejó muy grata memoria. Se encontró un día en inminente peligro de ser muerto por los bárbaros. Era muy estricto en guardar la disciplina religiosa, aún estando solito entre los indios. Supo juntar tan felizmente la vida activa con la contemplativa, que era difícil decir, a la cual era más aficionado. Casi por toda su vida se ocupaba siempre con lo más pesado y lo más humilde. [f. 373] En su avanzada edad tenía una muy quebrantada salud, así que muchas veces apenas se podía mover, por los dolores agudos que sufría en todo su cuerpo. Sin embargo, mostró en su postración una gran paciencia y conformidad con la voluntad de Dios, hasta que esperó para unirse a Dios en la eterna felicidad" (Salinas y Folkenand, 2017, pp. 82-83).

Debido a la escasa información aportada por el manuscrito Phrases Selectas y a lo poco que sabemos sobre José Coco, no hay forma de asegurar que él haya sido el organizador o compilador principal de este documento y el redactor de los paratextos. Sin embargo, existen algunos indicios que se han recopilado en esta sección: Coco es uno de los dos no hispano-parlantes nativos que estaban en San Francisco Javier en 1687; sus conocimientos y aptitudes eran similares a los que Restivo tendría unos años después; y como muchos lenguaraces del guaraní, estuvo por lo menos algunos años misionando entre los chiriguanos. Aunque esto pareciera indicar que es probablemente el jesuita que más contribuyó a esta actualización y reorganización del Tesoro de Montoya, resta todavía aludir a los otros colaboradores cuya presencia se adivina detrás del manuscrito.

\section{El rol de los colaboradores en Phrases Selectas}

El proceso de constitución de los libros (manuscritos o impresos) de la modernidad temprana era desde luego diferente al que conocemos hoy. En esta época, 
Vega. La posible autoría del manuscrito anónimo Phrases Selectas, entre el uno y el múltiple (Misiones Jesuíticas de...

elaborar un texto - más aún un texto lingüístico cuya finalidad es la evangelización de la población indígena - era a menudo reproducir fragmentos de materiales textuales previos, tal y como sucede en las recopilaciones de lugares comunes de la época (Chartier, 2008, pp. 27-28) o en la propia elección de las "phrases selectas" del libro aquí considerado. El único jesuita que se reconoce como figura con estatuto autoral en la portada del manuscrito es el limeño Antonio Ruiz de Montoya, autor del texto de base. En efecto, los impresos de mediados del siglo XVII de este misionero fueron infinitamente retomados y reconstruidos en el contexto de las misiones jesuíticas de guaraníes. Sin embargo, además de Ruiz de Montoya y del jesuita no hispano-parlante que firma los paratextos en San Francisco Javier, existen indicios de otros colaboradores involucrados en la construcción de este texto.

En la Tabla 3 incluimos la información que puede inferirse sobre estos colaboradores. Cada uno de los puntos incluidos en esta tabla se encuentra desde luego en un nivel hipotético y es pasible de ser sometido a discusión. No obstante, juzgamos que resulta útil para organizar la información de que disponemos acerca de quienes contribuyeron a dar a las producciones de la cultura textual misional la forma que hoy poseen.

Tabla 3. Niveles de colaboración identificables en el manuscrito Phrases Selectas.

\begin{tabular}{ll}
\hline \multicolumn{1}{c}{ Rol } & \multicolumn{1}{c}{ Phrases Selectas } \\
\hline Copistas & Indios anónimos de San Francisco Javier \\
\hline Compilador principal del texto & ¿José Coco? \\
\hline \multirow{2}{*}{ Informantes lingüísticos } & Jesuitas anónimos \\
\cline { 2 - 2 } & Indios anónimos de Santa María la Mayor \\
\cline { 2 - 2 } & Indios anónimos de San Francisco Javier \\
\hline Autor del texto base & Antonio Ruiz de Montoya \\
\hline
\end{tabular}

Phrases Selectas se presenta como una adaptación del Tesoro de la lengua guaraní (1639) de Antonio Ruiz de Montoya en función tanto de las condiciones dialectales peculiares de San Francisco Javier como de las necesidades de un aprendizaje más sencillo entre los misioneros jesuitas. El núcleo de base está tomado precisamente de este Tesoro. El paratexto final del libro, como lo indica su extenso título ("Varios vocablos, y modos de hablar no usados en San Javier ni en Santa María, pero por si acaso fueren usados en alguna parte de estas Reducciones los quiero poner aquí, citándote con fidelidad la hoja y columna del Tesoro del Venerable Padre Antonio Ruiz") es una sección basada en el libro de Ruiz de Montoya sin mayores alteraciones. La consideración de que esto implicaba únicamente una reescritura y la veneración y respeto que los jesuitas del Paraguay sostenían por Ruiz de Montoya son probablemente los factores que explican que este sea el único actor del que se reconoce un estatuto autoral en la portada. Borrar por completo a la figura del misionero del siglo XVII en la consideración de estos trabajos lingüísticos sería un error e implicaría desconocer la propia representación de los jesuitas de la época. 
El siguiente nivel es el de los informantes lingüísticos —indígenas y jesuitascuya existencia suponemos detrás de la escritura de Phrases Selectas, quienes pudieron prestar su ayuda oral o escrita al desarrollo del libro. La consideración de que debió haber otros jesuitas involucrados, además de Ruiz de Montoya y de quien hipotéticamente identificamos como José Coco, se basa fundamentalmente en algunas ideas tenidas en cuenta recientemente por la historiografía, como el planteo de un scriptorium jesuíticoguaraní (Obermeier y Cerno, 2013, pp. 47-51). Resulta en parte lógico pensar que la producción lingüística era en realidad una tarea colectiva - máxime entre 1687 y 1733 , cuando se produjeron variados materiales textuales novedosos en guaraní-. En cualquier caso, en uno de los paratextos se declara que se pensó explícitamente en los misioneros como destinatarios, lo cual deja abierta la posibilidad de una contribución más activa de estos. En el caso de los colaboradores indígenas, como ya se ha mencionado, en el prólogo al lector el jesuita menciona la práctica de lectura de párrafos del Tesoro a los indios de San Francisco Javier, quienes no los entendían. Esta interacción (un jesuita que lee, indios que oyen y probablemente explican, un jesuita que luego escribe) guarda una cierta similitud morfológica con la relación entre Pablo Restivo y Nicolás Yapuguay ${ }^{41}$ tal y como es descripta por Peramás ${ }^{42}$ : "[H]ubo otro indio por nombre Nicolás [Yapuguay], que trabajó grandemente en la confección de un Catecismo, escrito por él mismo y que el Padre Restivo, italiano, hizo que se imprimiera. El Padre Restivo le tuvo siempre a su lado como intérprete, siempre que quería explicarse en guaraní con mayor elegancia" (Furlong, 1962, p. 594).

La idea de una interacción creativa entre indígenas y jesuitas — aplicada ya a los libros lingüísticos de Restivo y a los textos religiosos de Yapuguay- ha sido defendida recientemente por Brignon para un caso de un libro en el que antes no se había aplicado, la traducción al guaraní de De la diferencia entre lo temporal y lo eterno de Juan Eusebio Nieremberg (Brignon, 2018). Además, la colaboración oral indígena coincide con la idea indicada por Rodríguez Alcalá de la oralidad como punto de partida de la lingüística guaraní (Rodríguez-Alcalá, 2010, pp. 17-21). De cualquier modo, el rol de estos colaboradores en Phrases Selectas, aunque relevante en lo referente a la cuestión dialectal, permanece en un plano indeterminado. A su vez, la existencia de este tipo de colaboradores introduce un elemento de circularidad entre jerarquías culturales. Se trata de un aspecto que ha sido resaltado por la historia cultural para los textos temprano-modernos (Ginzburg, 2016) y que debería retomarse a la hora de analizar los textos más eruditos producidos en contextos interculturales y de frontera. El siguiente nivel de autoría es el explicado con anterioridad y corresponde hipotéticamente a José Coco. Aquí Coco aparece como el organizador y compilador de toda la materia textual, combinando en este sentido el Tesoro de Ruiz de Montoya, su presunta experiencia

\footnotetext{
${ }^{41}$ Nicolás Yapuguay fue cacique, músico y escritor-teólogo guaraní. La mayoría de los datos de su vida son todavía desconocidos.

42 José Manuel Peramás nació en Mataró (Barcelona, España) en 1732, arribó a Montevideo en 1755 y falleció en Faenza (Ravena, Italia) en 1793. Es autor de varios escritos sobre la provincia jesuítica del Paraguay.
} 
Vega. La posible autoría del manuscrito anónimo Phrases Selectas, entre el uno y el múltiple (Misiones Jesuíticas de...

en variados pueblos (San Francisco Javier, Santa María la Mayor) y los aportes de los colaboradores indígenas y tal vez jesuitas.

El siguiente nivel corresponde a los copistas o amanuenses que se encargaron de la "puesta en limpio" del manuscrito. En este punto, no hay ninguna duda de que quienes efectuaron esta escritura a mano fueron indígenas. Esta era una práctica común en las misiones de guaraníes, y los jesuitas siempre dieron a entender que la habilidad para imitar a mano caracteres de imprenta era privativa de los guaraníes. Una descripción con la que contamos respecto de este rol es de Francisco Jarque ${ }^{43}$ :

“[L]os [guaraníes] que escriven llegan con su pluma a imitar tanto la mejor letra, que copian un Missal impresso en Antuerpia, con tal perfeccion, que es necessaria mucha advertencia para distinguir qual de los dos escrivió la mano del Indio. Y con este acierto copian una Sacra de los que sirven para la Missa, estampada en Roma, con varias Imagenes de la Passion, y Santos, toda la dibuja su pluma, como si fuera de molde. Assi en parte suplen los Missioneros la falta que ay de Imprenta alguna en toda aquella Provincia” (Xarque, 1687: pp. 342-343).

En este sentido, la portada de Phrases Selectas (Figura 1) resulta elocuente. Sin embargo, hay una referencia aún más explícita respecto de los copistas indígenas en el prólogo al lector. Allí leemos:

"Cuando encontrares con estos vocablos: corromper, desflorar u otros semejantes, y no hallares vocablo alguno de este Idioma guaraní, sepas que lo he hecho de propósito, porque como son vocablos menos limpios, no los he querido poner, para que los escribanos no hallen en qué tropezar, pero como es necesario el saberlos, te cito fielmente el Tesoro del Venerable Padre poniéndote la hoja, plana y párrafo de él, para que lo puedas hallar con facilidad"44.

La eliminación de las palabras de contenido sexual únicamente en guaraní se realizó, precisamente, para "preservar" a los copistas ("escribanos"), quienes probablemente ignoraban el castellano. El rol de estos amanuenses es muy importante en la medida en que, como lo ha enseñado Roger Chartier, no existen textos "aislados" y abstractos (en un sentido ideal platónico), sino que los textos poseen siempre una forma material específica (Chartier, 1992, pp. 53-56), en este caso un manuscrito encuadernado y con una caligrafía determinada. El manuscrito se diferencia así del impreso, en que dos ejemplares pueden tener una mayor similitud (nunca exacta, por lo menos en este período). Sin embargo, también en el caso de los impresos sería necesario considerar la

${ }^{43}$ Francisco Jarque nació en Orihuela (Alicante, España) en 1607, arribó a Buenos Aires en 1628 y falleció en Orihuela en 1691. Abandonó la Compañía de Jesús en 1637 pero mantuvo buenas relaciones con la misma.

${ }^{44}$ Buenos Aires. Museo Mitre, Biblioteca Americana, 14-4-41, Phrases Selectas..., "Amigo en Christo y benevolo lector", sin paginación. 
actuación de quienes se encargaban de dar una determinada forma material a un texto: correctores, cajistas o componedores, grabadores, etc. (Garone Gravier, 2014, pp. 42-51), roles que ocupaban jesuitas e indígenas en las reducciones de guaraníes (Wilde, 2014).

Existen pues varios aportes entremezclados en la producción del manuscrito lingüístico Phrases Selectas. No obstante, esta no es una peculiaridad de este documento, pues la idea puede ser aplicada a otros materiales de la cultura misional jesuítica. En muchas ocasiones, en efecto, nos encontramos frente a lo que anacrónicamente podrían considerarse problemas de autoría, puesto que en la cultura retórica de la época y en la naturaleza de estos textos catequísticos y lingüísticos en sentido estricto no existe una autoría fija, individual, subjetiva y original. Lo mismo sucede con otros objetos culturales que circularon en los contextos misionales, por ejemplo las composiciones musicales. Los musicólogos han demostrado que las producciones de famosos repertorios musicales, como el de Chiquitos, se caracterizan por la presencia de múltiples realizadores: compositores europeos, músicos jesuitas (en Europa, en el Paraguay), distintos copistas y transcriptores (indígenas o jesuitas), arregladores, etc. (Illari 1998 y Waisman 1998). Es incluso posible que los realizadores identificados por los historiadores no coincidan con la propia atribución de compositor que se encuentra en los documentos. Por lo demás, regresando a los libros, resta todavía llevar adelante un estudio de las concepciones autorales de los jesuitas de la época, por ejemplo, a través de qué figura se privilegia a la hora de atribuir autoralmente libros en lenguas indígenas en inventarios o catálogos. Una exploración preliminar sugiere que en los inventarios de las reducciones se enfatizan las figuras de Ruiz de Montoya y de Restivo y queda opacado el rol autoral de figuras indígenas como Nicolás Yapuguay ${ }^{45}$. Se trata, sin embargo, de un aspecto que merecería una investigación específica que no puede desarrollarse aquí.

\section{Conclusión: una constelación de lenguaraces}

A lo largo de este trabajo, hemos analizado la autoría del diccionario castellanoguaraní manuscrito Phrases Selectas (San Francisco Javier, 1687). Para esto, contrastamos la información presente en este texto — con respecto a fecha y lugar de producción y rasgos biográficos del jesuita que organizó el material - con los datos de los misioneros del Paraguay compilados en los catálogos de la Compañía de Jesús, conservados en el Archivum Romanum Societatis Iesu. A partir de variados indicios, hemos arribado a la conclusión de que el misionero sardo José Coco (1643-1717) es, probablemente, quien se encargó de revisar y actualizar el Tesoro de Ruiz de Montoya en este contexto de fines del siglo XVII. Además de la demostración de esta afirmación, uno de los objetivos principales de este artículo ha sido incorporar un elemento más - José Coco en tanto lenguaraz, esto es, especialista en la lengua guaraní- a la ya larga serie de indígenas y jesuitas que, a través de su producción, contribuyeron a la construcción de una cultura textual misional propia del Paraguay jesuítico, condición del proceso de conversión de los indígenas.

\footnotetext{
${ }^{45}$ Analizamos esta cuestión en un artículo en proceso de publicación.
} 
Vega. La posible autoría del manuscrito anónimo Phrases Selectas, entre el uno y el múltiple (Misiones Jesuíticas de...

Esta cultura textual es amplia y compleja y está conformada tanto por impresos como por manuscritos. Por variadas razones, no puede ser atribuida en su totalidad a Antonio Ruiz de Montoya - y tampoco a Pablo Restivo - En primer lugar, conocemos otros jesuitas e indígenas que escribieron libros que alcanzaron la imprenta y cuya autoría fue reconocida en la portada de los textos: José Serrano ${ }^{46}$, Nicolás Yapuguay, José de Insaurralde ${ }^{47}$. En segundo lugar, otros jesuitas pueden entenderse como organizadores, editores o, incluso, autores en sí mismos: posiblemente José Coco para el caso de Phrases Selectas, pero también otros jesuitas que produjeron información por ejemplo en el ámbito de la botánica, como Marcos Villodas ${ }^{48}$. En tercer lugar, hubo escritores específicamente indígenas cuya obra no alcanzó la imprenta: Peramás menciona uno por su nombre, Melchor, autor de una Historia del pueblo de Corpus Christi en guaraní, pero se sabe de la existencia de muchos más (Furlong, 1962, pp. 593-597). En cuarto lugar, y esto no es un aspecto menor, debemos incluir dentro de esta consideración a todos aquellos colaboradores (indígenas y jesuitas), a menudo anónimos, que contribuyeron a dar la forma material a los libros de esta cultura textual: amanuenses o copistas, cajistas o componedores, correctores, grabadores, informantes y ayudantes de todo tipo. Conocemos sólo los nombres de algunos de estos: Juan Bautista Neumann ${ }^{49}$, el propio José Serrano, Juan Yapari. Estos sujetos, identificados o anónimos, contribuyeron productiva y creativamente a la cultura textual que se desarrolló en el contexto de las misiones jesuíticas de guaraníes. La identificación probable de José Coco como lenguaraz y escritor tuvo el objetivo, pues, de incluir un elemento más a esta larga serie.

\section{Referencias Bibliográficas}

Avellaneda, M. (2014). Guaranies, criollos y jesuitas. Luchas de poder en las revoluciones comuneras del Paraguay, siglos XVII y XVIII. Asunción: Editorial Tiempo de Historia.

Barthes, R. (1994). "La muerte del autor”. En El susurro del lenguaje: más allá de la palabra y de la escritura (pp. 65-71). Paidós.

Brabo, F. J. (Ed.). (1872). Inventarios de los pueblos de misiones. Madrid: Imprenta y Estereotipia de M. Rivadeneyra.

Brignon, T. (2018). “Du copiste invisible à l'auteur de premier ordre. Le traduction collaborative de textes religieux en guarani dans les réductions jésuites du Paraguay". Sociocriticism, 33, 299-338. ISSN 0985-5939.

\footnotetext{
${ }^{46}$ José Serrano nació en Antequera (Málaga, España) en 1634, arribó a Buenos Aires en 1658 y falleció en Loreto (provincia de Misiones, Argentina) en 1713 (Storni, 1980, p. 269).

${ }^{47}$ José de Insaurralde nació en Asunción en 1663 y falleció en Candelaria (provincia de Misiones, Argentina) en 1730. Fue superior de las reducciones de guaraníes entre 1726 y 1729 (Storni, 1980, p. 146).

${ }^{48}$ Marcos Villodas nació en 1695 en Nanclares de Gamboa (Álava, España) en 1695, arribó a Buenos Aires en 1717 y falleció en Santa Fe (Argentina) en 1741 (Storni, 1980, p. 307).

49 Juan Bautista Neumann nació en Viena (Austria) en 1659, arribó a Buenos Aires en 1691 y falleció en Asunción en 1704 (Storni, 1980, p. 199).
} 
Castelnau L’Estoile, C. de. (2015). “«En raison des conquêtes, de la religion et du commerce». L'invention de la langue générale dans le Brésil du XVIe siècle”. Mélanges de la Casa de Velázquez. Nouvelle série, (45-1), 77-98. Recuperado de: https://journals.openedition.org/mcv/6147; https://doi.org/10.4000/mcv.6147.

Castelnau-L'Estoile, C. de. (2000). Les ouvriers d'une vigne stérile. Les jésuites et la conversion des Indiens au Brésil, 1580-1620. Paris: Centre Culturel Calouste Gulbenkian.

Chamorro, G. (2014). PHRASES SELECTAS: Un diccionario manuscrito castellanoguaraní anónimo. Corpus. Archivos virtuales de la alteridad americana, 4(2). Recuperado de: https://journals.openedition.org/corpusarchivos/1309; https:// doi.org/10.4000/corpusarchivos. 1309.

Chartier, R. (1992). “El mundo como representación”. En El mundo como representación. Estudios sobre historia cultural (pp. 45-62). Barcelona: Gedisa.

Chartier, R. (1994). “¿Qué es un autor?”. En Libros, lecturas y lectores en la Edad Moderna (pp. 58-89). Madrid: Alianza.

Chartier, R. (1996). Escribir las prácticas: Foucault, de Certeau, Marin. Buenos Aires: Manantial.

Chartier, R. (2008). Escuchar a los muertos con los ojos. Lección inaugural en el Collège de France. Buenos Aires: Katz Editores.

Daher, A. (2011). "De los intérpretes a los especialistas: el uso de las lenguas generales de América en los siglos XVI y XVII”. En G. Wilde (Ed.), Saberes de la conversión. Jesuitas, indígenas e imperios coloniales en las fronteras de la cristiandad (pp. 61-80). Buenos Aires: SB.

Estenssoro, J. C. (2015). "Las vías indígenas de la occidentalización. Lenguas generales y lenguas maternas en el ámbito colonial americano (1492-1650)”. Mélanges de la Casa de Velázquez. Nouvelle série, (45-1), 15-36. Recuperado de: https:// journals.openedition.org/mcv/6097; https://doi.org/10.4000/mcv.6097.

Estenssoro, J. C., \& Itier, C. (2015). "Présentation (dossier Langues indiennes et empire dans l'Amérique du Sud coloniale)". Mélanges de la Casa de Velázquez. Nouvelle série, (45-1), 9-14. Recuperado de: https://journals.openedition.org/mcv/6127.

Foucault, M. (2010). ¿Qué es un autor? Buenos Aires: El cuenco de plata.

Fraschini,A.E.(Ed.).(2005a). Index librorum Bibliothecae Collegii Maximi Cordubensis Societatis Jesu anno 1757: edición crítica, filológica y biobibliográfica (Vol. 1). Córdoba: Universidad Nacional de Córdoba.

Fraschini,A.E.(Ed.).(2005b). Index librorum Bibliothecae Collegii Maximi Cordubensis Societatis Jesu anno 1757: edición crítica, filológica y biobibliográfica (Vol. 2). Córdoba: Universidad Nacional de Córdoba.

Furlong, G. (Ed.). (1953). José Cardiel, S.J. y su Carta-Relación (1747). Buenos Aires: Librería del Plata.

Furlong, G. (1962). Misiones y sus pueblos de guaranies. Buenos Aires.

Garone Gravier, M. (2014). Historia de la tipografía colonial para lenguas indígenas. México: Centro de Investigaciones y Estudios Superiores en Antropología Social. 
Vega. La posible autoría del manuscrito anónimo Phrases Selectas, entre el uno y el múltiple (Misiones Jesuíticas de...

Ginzburg, C. (2016). El queso y los gusanos. El cosmos según un molinero del siglo $X V I$. Buenos Aires: Ariel.

Gorzalczany, M. A., \& Olmos Gaona, A. (2006). La biblioteca jesuitica de Asunción. Buenos Aires. Edición de los autores.

Illari, B. (1998). "Un Laudate pueri como antiobra (acerca de la invención de la música jesuítica de Chiquitos)". En Música Barroca del Chiquitos Jesuítico. Trabajos leidos en el Encuentro de Musicologos. Primer festival internacional de musica renacentista y barroca americana Misiones de Chiquitos (pp. 11-41). Santa Cruz de la Sierra: AECI.

Illari, B. (2006). "Carta de Misiones: sobre la música jesuítico-guaraní en 1651 y su investigación actual". Revista del Instituto de Investigación Musicológica "Carlos Vega", 20, 97-113. 1515-050X.

Lenguas Americanas. Catálogo ilustrado de la sección X de la biblioteca. (1912). Buenos Aires: Imprenta de Coni Hermanos.

Leonhardt, C. (Ed.). (1927). Cartas Anuas de la Provincia del Paraguay, Chile y Tucumán, de la Compañía de Jesús (1609-1614). Buenos Aires: Jacobo Peuser.

Lovay, S. M. (2017). Las bibliotecas en las estancias jesuíticas. El caso de Santa Catalina (Córdoba-Argentina). Antiguos jesuitas en Iberoamérica, 5(2), 166-200. Recuperado de: https://revistas.unc.edu.ar/index.php/ihs/article/view/17768; http://dx.doi.org/10.31057/2314.3908.v5.n2.17768.

Machoni, A. (1732). Las siete estrellas de la mano de Jesus. Tratado historico de las admirables vidas y resplandores de siete varones ilustres de la Compañia de Jesus, naturales de Cerdeña. Córdoba: Colegio de la Assumpción, por Joseph Santos Balbas.

Maldavsky, A. (2012). Vocaciones inciertas. Misión y misioneros en la provincia jesuita del Perú en los siglos XVI y XVII. Lima: CSIC.

Melià, B. (1979). "Breve introducción para aprender la lengua guaraní [Alonso Aragona, 1627]". Amerindia, 4, 23-62.

Melià, B. (1992). La lengua guarani del Paraguay. Historia, sociedad y literatura. Madrid: Editorial MAPFRE.

Melià, B. (2003). La Lengua Guaraní en el Paraguay colonial. Asunción: CEPAG.

Obermeier, F. (2017). El Apéndice de la Colección de obras impresas y manuscritas [1853] de Pedro de Angelis. Una reconstrucción de la parte etnolingüística. Antiguos jesuitas en Iberoamérica, 5(2), 3-27. Recuperado de: https://revistas.unc.edu.ar/index.php/ ihs/article/view/17758; http://dx.doi.org/10.31057/2314.3908.v5.n2.17758.

Obermeier, F., \& Cerno, L. (2013). "Nuevos aportes de la lingüística para la investigación de documentos en guaraní de la época colonial (Siglo XVIII)". Folia Histórica del Nordeste, 21, 33-56. ISSN: 2525-1627.

Rodríguez-Alcalá, C. (2010). "Apuntes para una historia de la escritura en guaraní: el estatuto y la circulación del texto en las misiones jesuíticas". Scriptura, (21), 9-32. ISSN: 1130-961X. 
Salinas, M. L., \& Folkenand, J. (Eds.). (2015). Cartas anuas de la Provincia Jesuitica del Paraguay. 1681-1692. 1689-1692. 1689-1700. Asunción: Centro de Estudios Antropológicos de la Universidad Católica.

Salinas, M. L., \& Folkenand, J. (Eds.). (2017). Cartas anuas de la Provincia Jesuítica del Paraguay. 1714-1720. 1720-1730. 1730-1735. 1735-1743. 1750-1756. 17561762. Asunción: Centro de Estudios Antropológicos de la Universidad Católica.

Storni, H. (1980). Catálogo de los jesuitas de la Provincia del Paraguay (Cuenca del Plata), 1585-1768. Roma: Institutum Historicum S.I.

Udaondo, E. (1945). Diccionario biográfico colonial argentino. Buenos Aires: Institución Mitre - Editorial Huarpes.

Waisman, L. (1998). "Schmid, Zipoli, y el "indígena anónimo": Reflexiones sobre el repertorio de las antiguas misiones jesuíticas”. En B. Illari (Ed.), Música Barroca del Chiquitos Jesuitico. Trabajos leidos en el Encuentro de Musicologos. Primer festival internacional de musica renacentista y barroca americana Misiones de Chiquitos. Santa Cruz de la Sierra: AECI.

Wilde, G. (2014). Adaptaciones y apropiaciones en una cultura textual de frontera: impresos misionales del Paraguay Jesuítico. História Unisinos, 18(2), 270286. Recuperado de: http://revistas.unisinos.br/index.php/historia/article/view/ htu.2014.182.06; https://doi.org/10.4013/htu.2014.182.06.

Wilde, G. (2016). "La invención de la religión indígena: adaptación, apropiación y mímesis en las fronteras misioneras de Sudamérica colonial". Anais de História de Além-Mar, XVII, 21-58. ISSN: 0874-9671.

Xarque, F. (1687). Insignes Missioneros de la Compañia de Jesús en la Provincia del Paraguay. Pamplona: Juan Micòn, Impressor. 